\title{
Cooperative Learning Boosts EFL Students' Grammar Achievement
}

\author{
Mohammad Reza Ghorbani \\ University of Bojnord, Bojnord, Iran \\ Email address: mrg872@yahoo.com \\ Maryam Nezamoshari'e \\ Ferdowsi University, Mashhad, Iran \\ Email address: m.nezamosharie@gmail.com
}

\begin{abstract}
It has been suggested that Cooperative Learning (CL), as a close relative of Community Language Learning (CLL), might be a good alternative to the dominant Grammar Translation Method (GTM) in Asia, where learners are believed to be individualistic, passive, and unable to work cooperatively to construct their own knowledge. Based on ten ninety-minute-long sessions, this study compared CL to GTM in north-east Iran, using an experimental design. This research investigated 64 female freshmen's achievement on 10 grammatical forms. Thirty-two students (eight four-member groups) participated in the experimental group (CL), and the other thirty two in the control group. The same instructor (one of the researchers) taught in both classes. Using the SPSS software, a covariance test and independent samples t-tests were used to test three hypotheses. A prescribed textbook at the national level was used as the material and a thirty-item test with a reliability of 0.82 was used as the instrument. The findings suggest the superiority of CL to GTM and its being applicable in an Iranian context. Furthermore, in the CL class, the gifted students were found to improve as much as the poor ones. The study offers some implication for teachers, teacher educators, students, and theory developers.
\end{abstract}

Index Terms - cooperative learning, traditional instruction, grammar and high/low-achievers

\section{INTRODUCTION}

The long-held grammar-teaching in language classes was hindered with the heyday of the communicative method of language teaching in the 1970s. The concept of grammar has been defined in a variety of ways; besides, various methods and techniques in the world of teaching English as a second/ foreign language (TESL/ TEFL) have added different colors and costumes to it, in the eyes of the learners. It has been defined, for instance, by Richards \& Schmidt (2010) as a description of different ways in which bits of linguistic value are or can be combined so that longer linguistic units by the name of sentences are made. Nunan (2003), further, classifies grammar into two categories; prescriptive grammar, dealing with what to do, and descriptive grammar, dealing with what there really is. Noteworthy is the fact that grammar was (and still is) either oppressed and thrown away since the rise of communicative revolution focusing on meaning, or dealt with in rigid teacher-fronted classes focusing on forms except for the case of some classes whose teachers focus on form (not forms), that is, form + meaning at the same time (Long \& Robinson, 1998).

Nowadays, nevertheless, there is some support for the idea of grammar instruction, which implies focus on form. Schmidt's (1990) Noticing Hypothesis and Swain's (1985) Output Hypothesis (cited in Swain \& Lapkin, 1995), for instance, maintain the fact that mere exposure to comprehensible input would not be sufficient for language acquisition to occur. In addition, Long (1983, cited in Nassaji \& Fotos, 2004) insisted that grammar instruction is inevitable and necessary to language acquisition. Furthermore, R. Ellis (2002, cited in Nassaji \& Fotos, 2004) concluded that extensive grammar instruction over a long period of time would lead to the construction of implicit knowledge in individuals. Therefore, as teaching grammar is useful and necessary, there should be a search for the most appropriate way of performing it.

As Liang (2002) puts it, cooperative learning (CL) is very close in nature to the principles of Communicative Language Teaching (CLT). Thus, CL was chosen by the researchers as the method under experiment as an alternative to the traditional instruction (TI) in Iran.

English in Iran is currently a significant part of all university majors (Eslami, Eslami-Rasekh, \& Quiroz, 2007, cited in Eslami, 2010). However, teaching English is summarized into requiring students to read English texts and translate them into Persian, that is, GTM is still dominant in Iran (Eslami, 2010; Ghorbani, 2009). Hence, the need to find an alternative to GTM was the first factor that motivated this study.

The innovation of CL has roots in hundreds of years ago, with its developed application at the US schools in the 1960s and 1970s against the then-familiar GTM (Richards \& Rodgers, 2002). CL is supported by such key figures as Vygotsky (1978), Long (1996, cited in Brown, 2000), Krashen (1985, cited in Richards \& Rodgers, 2002), and Bandura (1997), to mention a few. Olsen and Kagan (1992, p.8, cited in Richards \& Rodgers, 2002) define CL as follows: 
Cooperative learning is group learning activity organized so that learning is dependent on the socially constructed exchange of information between learners in groups and in which each learner is held accountable for his or her own learning and is motivated to increase the learning of others.

In choosing what method to use in a class, a teacher should have a sense of plausibility, to use Prabhu's (1990) term. That is, teachers should try a method themselves to see if it works in their context. For instance, CL is believed to be globally applied successfully (Johnson \& Johnson (1998, cited in Liang, 2002). Nonetheless, some researchers believe it cannot be applied well in Asia - including Iran - where students are supposed to be passive consumers of knowledge and cannot go beyond what they have been spoon-fed (Gow \& Kember, 1990, Go \& Mok, 1995, cited in Liang, 2002). Moreover, Thanh-Pham, et al. (2009 as cited in Thanh, 2011) in their meta-analysis reported that more than $50 \%$ of the studies about CL in Eastern contexts found it inappropriate. What makes the waters muddier is that CL is still unknown to Iranian universities where GTM with rigid roles for learners as passive recipients and mere audience, and teachers as lecturers and decision makers is dominant (Eslami, 2010; Ghorbani, 2009). Thus, to see if Iranian students are really Asian passive students and if CL is applicable in Iran, the present study was conducted.

Moreover, it seems essential to consider students with different levels of academic achievement (i.e., high-achievers or gifted vs. low-achievers or poor students), regarding the extent to which they might take advantage of CL. However, the fact that too few studies with diverse results have focused on this problem (e.g., Matthews, 1992; Parveen, et al., 2011; Hajilari, 2001) was the second reason motivating the current study. This study addressed the following research questions:

1. Is there a significant difference between the experimental group (CL) and control group (TI) regarding their grammar achievement?

2. Is there a significant difference between the high and low achievers in the CL class regarding their grammar achievement?

3. Is there a significant difference between the high and low achievers in the TI class regarding their grammar achievement?

To answer these questions, the following null-hypotheses were formulated:

1. Ho1: There is no significant difference between experimental group (CL) and control group (TI) regarding their grammar achievement.

2. Ho2: There is no significant difference between the high and low achievers in the CL class regarding their grammar achievement.

3. Ho3: There is no significant difference between the high and low achievers in the TI class regarding their grammar achievement.

\section{LITERATURE REVIEW}

The related literature is both for and against CL, in both EFL and ESL contexts. Reviewed here are first the literature comparing CL with TI, and then that of comparing gifted and poor students. Mostly the literature supports CL. For instance, Cohen \& Kulik (1981) meta-analyzed 65 CL studies and reported the outperformance of 87\% of the CL classes as compared to their control counterparts. Six years later, Good and Brophy (1987, cited in Momtaz \& Garner, 2010) in their meta-analysis of 41 studies found that $63 \%$ of them supported CL, 34\% showed no significant difference between the experiment and control groups, and $2 \%$ was against CL. In China, Zuo (2011) examined the effects of three methods of CL on reading comprehension and recommended it as a useful device.

Hajilari (2001) compared CL vs. (TI) on some Iranian junior high school students regarding their academic achievement. He reported the success of the CL class. In an Iranian context of university students, Behjat (2011) compared individualistic reading comprehension to collaborative one and reported the success of the latter. Zarei and Keshavarz (2011) studied the effects of two models of CL on reading comprehension and vocabulary learning, with 132 Iranian participants. They reported the success of the CL models as compared with the non-cooperative control groups. Javadi Rahvard (2010) investigated the effects of CL on 16 Iranian students's - as compared with control group reading comprehension ability. She proved CL as successful compared with the individually working control group. Momtaz and Garner (2010) focused on some Iranian students' reading comprehension through CL and proved it to be successful as well.

Despite its global popularity (Johnson \& Johnson, 1989, Kessler, 1992, cited in Liang, 2002) CL is not reported as very successful in nonwestern contexts. The results of a meta-analysis of a series of studies about CL in Eastern contexts by Tanh-Pham et al. (2009, cited in Thanh, 2011), for instance, showed that 50\%, and even more, of those studies were against CL, as compared to the traditional classes. Thanh (2011) in a survey interviewed 40 university students and 40 teachers from Vietnam on CL in that country. The majority of them- $65 \%$ of the students and $60 \%$ of the teachers - expressed their disapproval of CL. Thanh mentioned cultural barriers as the main reason for this failure in Vietnam. Kou (2011) studied CL in a British EFL setting. Generally, CL was not reported as facilitative to language acquisition. Other evidence comes from Pakistan, where Parveen et al., (2011) compared CL and TI, regarding the students' academic achievement. The findings suggested no significant difference between the two groups. Moreover, Clark (2008) mentions culture as a barrier to successful CL in Japan. 
Few studies have been on the effects of CL on the acquisition of grammar. Wang (1992) reported the superiority of the CL group to the traditional one in the study regarding grammar acquisition. Sharifi-Ashtiani (2010) examined the effects of cooperative test-writing on 60 female Iranian high school students' grammar acquisition. It was revealed that the CL class outscored the traditional class in their post-tests.

Most of the related literature is on comparing CL to TI, and too little of it has been on gifted vs. poor students in the CL classes. Hajilari (2001), for example, focused on a sample of Iranian students' academic achievement and concluded that not only is CL superior to TI, but also both the gifted and poor students developed equally in the CL class. Armstrong (1999, cited in Parveen et al., 2011) compared two CL groups: one group consisting of only gifted students and the other one consisting of heterogeneous ones. The results showed that both groups improved regarding their academic achievements. However, the gifted group stood a little higher. Evidence also comes from Western contexts. Matthews (1992) conducted a needs analysis, interviewing 15 gifted students in Mexico, and they all expressed their approval of working in homogeneous cooperative groups. Outside the field of English, CL has also been proved to be effective. Iqbal (2004, cited in Parveen et.al. 2011) compared CL with TI in teaching mathematics. The results were for CL, with poor students taking more advantage — compared with their gifted counterparts — of the CL program. Based on the above mentioned literature the researchers conducted the present study.

\section{METHOD}

The study included 62 female freshmen majored in different fields - from Law to Accounting, to Economics - at Ashkhane Distance Learning University, Ashkhane, north-east Iran. All of them were native speakers of Persian. Their ages ranged between 18 and 20. They were all accepted in that university through the yearly nation-wide-held University Entrance Examination in Iran. The participants were randomly divided into two groups of experiment (CL) and control (TI). Each class consisted of 32 learners. Both groups were taught by the same instructor-one of the researchers.

After preliminary checks were conducted to ensure there was no violation of the assumptions of normality, linearity, homogeneity of variances, an analysis of variance (ANCOVA), a pretest-posttest randomized experimental design, was used in this study to test the first hypothesis by controlling the pre-test scores statistically. ANCOVA removes the obscuring effects of pre-existing individual differences among participants. Then, Independent samples t-tests were used to test the second and third hypotheses.

The study was based on ten ninety-minute-long sessions of General English course each week, within a period of two and a half months, in the first semester of the 2011-2012 academic year. Alimohammadi and Khalili's (2008) textbook was the only material covered in the two classes. It consists of 10 chapters, with one grammatical point focused on in each. The ten grammatical points were: 1. Adjective Clause; 2. Adverb/Adjective/Noun Word Order; 3. Adverb Clause; 4. Active/Passive Voice; 5. Adjective Phrase; 6. Conditional Sentences; 7. Gerund; 8. Gerund Phrase; 9 . Noun Clause; and 10. Pronouns. There are mechanical drills on the grammatical points, which were focused on in both classes, but in different ways: learner-centered (CL) vs. teacher-centered (TI).

A decade's previous nation-wide Distance Learning General English final examinations-which are accepted as reliable, valid and practical in Iran-were the basis of the pre/post-tests. Those tests assess only vocabulary and grammar, thus, regarding the purpose of this study, in each test the items on grammatical points were chosen. Next, the repetitive items were left out, and totally 30 items were chosen randomly, with three items on each of the 10 chapters of the textbook. The same test was used as both the pre-test and post-test. Although the nation-wide-held Distance Learning University final examinations are believed to be reliable, the reliability of the pre/post-test was once more assessed through being given to a number of 30 students from that university who had passed the course the previous term. The KR-21 formula was used, and the reliability was estimated at 0.82 , which is considered by experts in this field as a high level of reliability (Farhady, et al., 2005).

Using the SPSS software, the independent samples t-test was used to compare the gifted vs. poor students' performances on their pre-tests and post-tests. To estimate both groups' knowledge on the specific grammatical points covered in their textbook before the instruction, the pre-test was given to them before the classes started. The 32 students in that class were divided into eight groups of four (Richards \& Rodgers, 2002). Following Larsen-Freeman (2003), the groups were heterogeneous regarding their grammatical knowledge on the specific grammatical forms, based on their pre-test scores. In other words, it was tried to have students with as different pre-test scores as possible in the same group. According to their pre-test scores the students in the CL class were divided into three groups of 11 poor students, 10 medium-achievers, and 11 gifted ones. This was done by first ranking their pre-test scores, then choosing the 11 lowest scores as the low achievers, and the 11 highest ones as the high-achievers.

In the CL class, at the beginning of the first session, following Richards \& Rodgers's (2002) recommendation for teachers, the teacher determined heterogeneous groups, explained about the rules and purpose of CL, motivated students to forget about the long-held competition in traditional classes and be more cooperative, and reminded them of the fact that they can learn from each other. She had explicitly instructed the necessary social skills, e.g. asking for help, continuing the conversation, respecting other students' rights, and supporting and encouraging their group mates. Before each activity, she would set a time limit. While they were doing the drill, she walked in the class, interacted with the students, provided them with the necessary feedback, answered their questions, and if necessary, taught the point 
again. In the CL class the teacher talked less than she did in the traditional one. She tried to facilitate the learning process, not to spoon-feed the learners. Students were responsible for their own learning. They were taught to organize and monitor their learning and provide feedback to their group mates.

Moreover, following Johnson and Johnson (1999) the learners in the CL class were positively interdependent; i.e. they mutually supported each other in a group, developing the theme that they could sink or swim all together, both gifted and poor students. They also retained their teacher-given roles in their groups during the cooperative activities. They knew well that an individual could represent the whole group and have a voice in the class. The learners interacted with each other face to face, following the social skills they had been taught by the teacher before. Furthermore, they continuously processed and evaluated their own groups' progress and tried to find better ways to improve the cooperative results.

In the CL class the teacher broadly mentioned the grammatical points, gave brief explanations, and raised broad questions in order for the students to think. On the contrary, in the traditional class the teacher explained each and every point about the grammatical points - the typical characteristic of GTM (Larsen-Freeman, 2003), and the typical teacher activity in Iranian classes (Eslami, 2010; Ghorbani, 2009). While in the CL class the students tried to do the drills cooperatively, in the traditional class they acted individually with a sense of competition and fear of not being able to do the drills correctly or not having the chance to express themselves if they knew the answer.

At the end of the first session, the students in the CL class were interviewed informally on their attitudes towards CL. The gifted students confessed to have been shocked and a little reluctant to share their knowledge and good marks with their group mates. The poor students, too, had been shocked to have the opportunity to be expressed and ask their questions freely from a classmate, rather than a teacher, without feeling stressed to lose face. Gradually, however, almost all of them were used to this way of learning. Throughout the semester, the students in the CL class showed more interest and enthusiasm to take part in the class activities and not to be absent, as compared with their counterparts in the traditional class.

According to Johnson \& Johnson's (1999) classification of CL groups, the eight groups in the CL class had heterogeneous members, lasting for ten weeks. Slavin's (1978, cited in Zuo, 2011) method of CL, namely, Student Teams-Achievement Divisions (STAD) was used throughout the study. Richards and Rodgers (2002) and Olsen and Kagan (1992) mentioned three types of CL activities, namely, Think-pair-share, Roundtable, and Numbered Heads. All three types of activities were used in the CL class in this study. In the Think-pair-share activities each of the eight groups was given a different drill. The students in each group first were asked to do the drills individualistically; next, they compared their answers with those of their group mates'. Finally, one student from each group explained the answer to the whole class. In Roundtable activities, each group took one piece of paper and the group mates took turns to do the drills and write their arguments for coming to that answer. In Numbered Heads activities, the teacher first gave a number to each student in each group - from one to four. After she asked a question or wanted the class to do a special drill, all of the students in each group thought about the answer, explained their answers to their group mates, and made sure that all of their group mates understood everything. The teacher then called a number-e.g. four-and all of the number fours in all groups raised their hands and, not unlike traditional classes, one student was chosen by her to answer the question. In all three types of activities whatever mark the representative student got was given to all of the students in that group.

Both the teacher and the students used their first language (L1), Persian, in the classes. That was due to the students' low level of language proficiency and also lack of time. In addition, L1 should not be considered as a taboo in classrooms; rather, it may even be a facilitator of learning (Brown, 2000). To estimate and compare the effects of the CL vs. TI, at the end of the tenth session the post-test was given to both classes. The results are discussed below.

\section{RESULTS}

The results of the study are summarized in the following tables.

TABLE 1:

STATISTICAL DESCRIPTION OF PRE- AND POST-TEST SCORES OF BOTH GROUPS

\begin{tabular}{|l|l|l|l|l|}
\hline Experimental Group & Mean & Std. Error & Mean & Std. Error \\
\hline pretest & 8.03 & 3.86 & 8.41 & 3.75 \\
\hline Post test & 21.25 & 3.87 & 17.16 & 6.17 \\
\hline $\begin{array}{l}\text { Post-test after neutralizing } \\
\text { the pre-test effect }\end{array}$ & 21.08 & .87 & 17.31 & .87 \\
\hline
\end{tabular}

TABLE 2:

RESULTS OF THE COVARIANCE TEST

\begin{tabular}{|l|l|l|l|l|l|}
\hline Effect & df & Mean Square & F & Sig. & $\eta^{2}$ \\
\hline Group & 1 & 329.169 & 52.551 & .000 & .463 \\
\hline Error & 61 & 6.264 & & & \\
\hline
\end{tabular}


Table 1 and 2 indicate that the first null-hypothesis (There is no significant difference between experimental group (CL) and control group (TI) regarding their grammar achievement.) is rejected because there is a significant difference between the two groups regarding their grammar achievement.

TABLE 3:

INDEPENDENT SAMPLES T-TEST OF THE HIGH AND LOW ACHIEVERS IN CL GROUP

\begin{tabular}{|l|l|l|l|l|}
\hline Group & $\mathrm{N}$ & $\begin{array}{l}\text { Post-test mean increase in } \\
\text { comparison to pre-test }\end{array}$ & Std. Deviation & Sig. \\
\hline Low achievers & 11 & 13.1818 & 1.83402 & \multirow{2}{*}{.340} \\
\hline High achievers & 11 & 12.1818 & 2.85721 & \\
\hline
\end{tabular}

Table 3 shows that the second null-hypothesis (There is no significant difference between the high and low achievers in the CL class regarding their grammar achievement.) is retained, that is, both the high and low achievers took advantage of CL equally.

TABLE 4:

INDEPENDENT SAMPLES T-TEST OF THE HIGH AND LOW ACHIEVERS IN TI GROUP

\begin{tabular}{|l|c|l|l|l|}
\hline Group & $\mathrm{N}$ & $\begin{array}{l}\text { Post-test mean increase in } \\
\text { comparison to pre-test }\end{array}$ & Std. Deviation & Sig. \\
\hline Low achievers & 11 & 6.2727 & 1.42063 & \multirow{2}{*}{.000} \\
\hline High achievers & 11 & 11.0000 & 1.84391 & \\
\hline
\end{tabular}

Table 4 shows that the third null-hypothesis (There is no significant difference between the high and low achievers in the TI class regarding their grammar achievement.) is rejected, that is, the high achievers took more advantage of TI than low achievers.

\section{DISCUSSION}

That CL proved to be superior to TI is in line with most of the research in Western contexts (Good \& Brophy, 1987, cited in Momtaz \& Garner, 2010; Cohen \& Kulik, 1981), and against most of the related literature in Eastern contexts (Tanh-Pham et al., 2009, cited in Thanh, 2011; Gow \& Kember, 1990, cited in Liang, 2002, to mention a few). The results can be explained in different ways.

Vygotsky's (1978, 1986) Zone of Proximal Development (ZPD) is the first reason. ZPD is that much knowledge that a student owns through which he/she cannot solve a problem alone, but if some instruction is received, he/she can solve the same problem (Vygotsky, 1978, 1986). In his view, learning is social, with an emphasis on dialogue. The CL class did receive instruction from the teacher, so in Vygotskian terms the drills were in their ZPDs. Working in groups, the students provided the necessary extra instruction to each other. Vygotsky's ZPD has originally been used for expert/novice interaction, but it can also be used in a neo-Vygotskian way (Storch, 2002, cited in Clark, 2008), i.e. peer/peer interaction - the case in the present study. This can be a rational reason for the poor students' development in the CL class. The gifted students who played the role of an expert developed significantly, too, as compared to their counterparts in the traditional class, and as much as the poor students did. In conversing and tutoring their group mates, the gifted students used the third function of speech, i.e. thinking with language (Vygotsky, 1978, 1986). Their counterparts in the traditional class did not have any dialogue with their classmates or the teacher, so language could not improve their thought. After all, according to Vygotsky $(1978,1986)$ cognition is not just in an individual's head; it is distributed in his/her head and the environment. The gifted students in the CL class used both their own minds and the environment (i.e. their group mates' minds and the opportunity to tutor what they had received from the teacher).

This superiority can also be explained through Swain's Output Hypothesis (Swain \& Lapkin, 1995), which considers mere input and teacher-talk as insufficient. It states that for language acquisition to happen, students need to have revised comprehensible output, besides intelligible input. During the CL activities, the students tried to have revised output. Of course their cooperatively produced revised output was written, not spoken. In addition to the poor students, the gifted ones tried to have revised output, which can be a reason for their having equally been improved.

Long's (1996, cited in Brown, 2000) Interaction Hypothesis, which requires meaningful communication besides comprehensible input as the necessary condition for language learning to occur, is also another factor supporting the success of CL.

In addition, through CL, the students did not encounter a high affective filter (Krashen, 1985, cited in Richards \& Rodgers, 2002). Since they could ask their questions and express themselves to their classmates, rather than a teacher, they were less anxious than their counterparts in the traditional class. Therefore, the affective filter was low enough for them to acquire the grammatical forms. Furthermore, peer feedback within the CL groups could be a manifestation of Krashen's (1985, cited in Richards \& Rodgers, 2002, Brown, 2000) concept of i+1 and comprehensible input which helped to the acquisition.

Moreover, according to Bandura (1997), whatever an individual chooses to do has been affected by his/her selfefficacy which causes him/her to pursue attainable, challenging and rewarding goals. In Bandura's (1988) opinion, individuals can learn by observing and following some models. This was noticeable in the CL class, where students observed their peers doing the same exercises, so that they built self-efficacies and noticed the drills as attainable and 
rewarding. The same was true with the gifted students who observed their teacher as their model. CL also finds some roots in Behaviorism. Based on Bandura (1971), a learner can learn by seeing both himself and other learners being encouraged and/or discouraged. This was a common scene in the CL class where different students with diverse levels of knowledge and academic achievement were either encouraged or discouraged by the teacher, which led to their learning and, in turn, to their classmates' learning.

Schmidt's (1990) Noticing Hypothesis also has a role in explaining the success of the CL class. According to this hypothesis, mere exposure to input (as in the case of the traditional class) is not enough for language acquisition to happen. Students should notice the form and meaning themselves (as in the case of the CL class).

Larsen-Freeman (1997) views language learning as a dynamic system. In that case, the CL class could be regarded as an open system, and the traditional class, as a closed one. The open system receives feedback and is open to the outside world (there is conversation between the students, and also between the students and the teacher), therefore becomes more regular and complex and learning happens. The closed system, however, has no relation with the outside world (no feedback is received) and finally 'settles down to a fixed point attractor' (Larsen-Freeman, 1997, p.152), and therefore, no learning happens.

To summarize this part, it should be mentioned that almost all of the students in the CL class developed their critical thinking ability and could regulate their performances (Vygotsky, 1978) on the post-test which was a similar occasion to the drills they had done cooperatively before. In fact, they first learned socially and then individually (Vygotsky, 1978).

\section{CONCLUSION}

The current study confirms the idea of CL as superior to traditional teacher-fronted classes and applicable in a small class in an Iranian EFL context. Therefore, the findings are in contrast with some part of the related literature which considers Eastern and Asian students as passive consumers of knowledge and unable to work cooperatively and rely on their own and their peers' knowledge (Gow \& Kember, 1990, Go \& Mok, 1995, cited in Liang, 2002; Thanh-Pham et al., 2009, cited in Thanh, 2011). Moreover, the findings of this study proved both the gifted and poor students to have equally taken advantage of the program.

This study is wished to be a beam of hope to those teachers all around the world and especially in Asian countries who are reluctant to apply CL in their classes lest they fail and waste their time. Teacher educators are also required to reconsider and defend the concept of CL in non-western contexts.

The fact that both the gifted and poor students developed equally is mostly to both teachers and students'-especially the gifted ones - concern who might be unwilling to accept the concept of CL (e.g. Matthews, 1992).

Moreover, the findings of this study confirm Vygotsky's (1978) concept of Dynamic Assessment, since post-test scores were higher than the pre-test ones as a result of the delivered instruction - a point to teachers and teacher educators' concern.

Furthermore, the opportunity given to the students, especially the poor ones, in the CL class to freely express themselves, have a voice in the class, and improve their critical thinking-what they have long been deprived of in the teacher-fronted classes - might have a 'butterfly effect' (Gleick, 1987, p.8, cited in Larsen-Freeman, 1999, p.144) on their education and their whole life.

The results also have implications for theory developers. As a matter of fact, this study confirmed CL which is in turn supported in different models of second/foreign language acquisition. As mentioned before, Krashen's (1985, cited in Richards \& Rodgers, 2002) Affective Filter Hypothesis in Innatism, Long's (1986, cited in Brown, 2000) Interaction Hypothesis and Swain's (1985, cited in Swain \& Lapkin, 1995) Output Hypothesis in Constructivism, Bandura's (1971) Social Cognitive Theory in Neo-Behaviorism, and last but not least, Vygotsky's (1978) ZPD in Social Constructivism support CL in some ways.

Points of further research might refer to first, studying the extent to which students can retain the acquired knowledge; second, comparing two CL classes of students, one consisting of heterogeneous students and the other consisting of homogeneous gifted ones; and third, considering students' EQ, IQ, gender, and major as independent variables to which their language acquisition in CL groups depends.

The researchers hope that this study will shed some light on the vague concept of CL in Asian countries as well as teachers and students' uncertainty.

\section{REFERENCES}

[1] Alimohammadi, M., \& Khalili, H. (2008). General English. Tehran: Payame Noor University Press.

[2] Bandura, A. (1971). Social learning theory. NJ: Prentice Hall Regents.

[3] Bandura, A. (1988). Organizational application of social cognitive theory. Australian Journal of Management, 13(2), $275-302$.

[4] Bandura, A. (1997). Selfefficacy: The exercise of control. New York: W. H. Freeman and Company.

[5] Behjat, F. (2011). Reading through interaction: From individualistic reading comprehension to collaboreadig. Theory and Practice in Language Studies, 1(3), 239-244.

[6] Brown, H. D. (2000). Principles of language learning and teaching. Fourth edition. White Plains, NY: Pearson Education. 
[7] Clark, I. (2008). Collaborative learning: The cultural barrier to effective language acquisition in Japanese classrooms. Journal of English as an International Language, 3, 99-126.

[8] Cohen, P. A. \& Kulik, J. A. (1981). Synthesis of research on the effects of tutoring. Research Information Research, 39, $227-$ 229.

[9] Eslami, Z. (2010). Teachers' voice vs. students' voice: A needs analysis approach to English for academic purposes (EAP) in Iran. English Language Teaching, 3(1), 3-11.

[10] Farhady, H., Jafarpoor, A., \& Birjandi, P. (2005). Testing language skills from theory to practice. Tehran: SAMT.

[11] Hajilari, E. (2001). A comparison between effects of cooperative and traditional learning on third-grade junior high school students' academic development. (Master's thesis, Islamic Azad University of Central Tehran, 2001). Retrieved on 8/12/11 from http://www.hawzah.net/FA/thesisview.html?ThesisID=87147

[12] Javadi Rahavard, Z. (2010). Cooperative learning strategies and reading comprehension. California Linguistic Notes, 35(2), 115.

[13] Johnson, D. W. \& Johnson, R. T. (1999). Making cooperative learning work. Theory into Practice, 38(2), 67-73.

[14] Kuo, I. (2011). Student perceptions of student interaction in a British EFL setting. ELT Journal, 65(3), 281-290.

[15] Larsen-Freeman, D. (1997). Chaos/complexity science and second language acquisition. Applied Linguistics, 18(2), 141-165.

[16] Larse-Freeman, D. (2003). Techniques and principles in language teaching. Oxford: Oxford University Press.

[17] Liang, T. (2002). Implementing cooperative learning in EFL teaching: Process and effects. (Doctoral dissertation, National Taiwan Normal University, 2002). Retrieved on 2/19/12 from http://www.asian-efl-journal.com/Thesis_Liang_Tsailing.pdf

[18] Long, M. H., \& Robinson, P. (1998). Focus on form: Theory, research, and practice. In C. Doughty and J. Williams (Eds.), Focus on form in classroom second language acquisition (15-42). Cambridge University Press.

[19] Momtaz, E. \& Garner, M. (2010). Does collaborative learning improve EFL students' reading comprehension? Journal of Linguistics and Language Teaching, 1(1), 15-36.

[20] Nassaji, H. \& Fotos, S. (2004). Current developments in research on the teaching of grammar. Annual Review of Applied Linguistics, 24, 126-145.

[21] Nunan, D. (2003). Practical English language teaching. New York: MC Graw-Hill.

[22] Parveen, Q., Mahmood, S. T., Mahmood, A. \& Arif, M. (2011). Effect of cooperative learning on academic achievement of $8^{\text {th }}$ grade students in the subject of social studies. International Journal of Academic Research, 3(1), 950-954.

[23] Prabhu, N. S. (1990). There is no best method-why? TESOL Quarterly, 24(2), 161-176.

[24] Richards, J. C., \& Rodgers, T. S. (2001). Approaches and methods in language teaching. Second edition. Cambridge: Cambridge University Press.

[25] Richards, J., \& Schmidt, R. (2010). Longman dictionary of language teaching and applied linguistics (4 ${ }^{\text {th }}$ ed.). London: Longman.

[26] chmidt, R. (1990). The role of consciousness in second language learning. Applied Linguistics, 11(2), 129-158.

[27] Sharifi-Ashtiani, N. (2010). Effects of cooperative test-writing on students' learning English and their attitudes towards it. Educational Innovations, 9(34), 25-44.

[28] Swain, M. \& Lapkins, S. (1995). Problems in output and the cognitive process they generate: A step towards second language learning. Applied Linguistics, 16(3), 371-391.

[29] Vygotsky, L. (1978). Mind in society: The development of higher psychological processes. Cambridge, MA: Harvard University Press.

[30] Vygotsky, L. (1986). Thought and language. Massachusetts: MIT Press.

[31] Wang, H. M. (1992). Using cooperative learning in the EFL classroom. National Taiwan Police College Bulletin, 5, $289-312$.

[32] Zarei, A. \& Keshavarz, J. (2011). On the effects of tow models of cooperative learning on EFL reading comprehension and vocabulary learning. Modern Journal of Language Teaching Methods, 1(2), 39-54.

[33] Zuo, W. (2011). The effects of cooperative learning on improving college students' reading comprehension. Theory and Practice in Language Studies, 1(8), 986-989.

Mohammad Reza Ghorbani is Assistant Professor of Teaching English as a Second Language (TESL) at the University of Bojnord, Bojnord, Iran. He has worked as an EFL teacher and researcher in Iran, Japan, and Malaysia since 1990. He has published three books on educational issues and one in Germany as well as eleven articles in specialized international journals. He has also presented six papers in international conferences. His interests are English Teaching, Learning, Testing, and Evaluation.

Maryam Nezamoshari'e is an M.A. in Teaching English as a Foreign Language (TEFL) from Ferdowsi University of Mashhad, Iran. She got her B.A. in English Literature from Ferdowsi University, Mashhad, Iran, in 2006. She has worked as an EFL teacher since 2007. She is currently teaching general English and English for academic purposes at different universities in north-east Iran. Her research interests are focus on form and ELT methodology. 